\title{
Episodic and semantic components of the compound-stimulus strategy in the explicit task-cuing procedure
}

\author{
CATHERINE M. ARRINGTON and GORDON D. LOGAN \\ Vanderbilt University, Nashville, Tennessee
}

\begin{abstract}
The explicit task-cuing procedure is commonly used to study executive control processes involved in set switching, but performance in this task-switching procedure may be accomplished without switching tasks. Subjects may perform both tasks by using a compound-stimulus strategy, in which subjects encode the cue, encode the target, and use the combination as a compound retrieval cue to choose the appropriate response. We manipulated the number of targets $(8,16,32$, or 640$)$ that subjects experienced in a four-cue/two-task procedure to separate episodic and semantic memory retrieval components of the compound-stimulus strategy. Cue repetitions were faster than task repetitions, and task repetitions were only slightly faster than task alternations, suggesting that cue repetition effects account for the bulk of the difference between repetitions and alternations. We found the same effects with all target set sizes. The results are consistent with use of a semantic compound-stimulus strategy.
\end{abstract}

The coordination of perceptual, cognitive, and motor processes to serve a given goal and the ability to reconfigure these processes in response to changes in goals are considered to be executive control processes (Logan, 1985; Meyer \& Kieras, 1997; Norman \& Shallice, 1986). The study of executive control in the cognitive psychology laboratory generally involves situations in which goals governing task performance must be instantiated, maintained, or switched in the context of competing demands. The explicit task-cuing procedure is frequently used to study processes of executive control (Meiran, 1996; Sudevan \& Taylor, 1987). The purpose of this article is to examine the role of episodic and semantic memory retrieval strategies in this procedure.

In the explicit task-cuing procedure, two or more tasks are interleaved within a block of trials in a random order, and an explicit cue indicates which task to perform on the current trial. Since tasks are interleaved, individual trials can be either task repetitions or task alternations. Response time (RT) is typically shorter for repetitions than for alternations. The difference in RT provides a measure of switch costs. Switch costs are commonly thought to reflect the time necessary to carry out an en-

This research was supported by National Institute of Mental Health Grant F32MH69046-01 and National Science Foundation Grants BCS 0133202 and BCS 0218507 . We thank Julie Delheimer and Courtney Shipper for their help in data collection and analysis. We also thank Ulrich Mayr, Akira Miyake, and an anonymous reviewer for their helpful comments on an earlier draft of this article. Correspondence concerning this article may be addressed to C. M. Arrington or G. D. Logan, Department of Psychology, 111 21st Ave. S., Vanderbilt University, Nashville, TN 37203 (e-mail: kate.arrington@vanderbilt.edu or gordon.logan@ vanderbilt.edu). dogenous act of set switching (Arrington, Altmann, \& Carr, 2003; Arrington \& Logan, 2004; Logan \& Gordon, 2001; Meiran, 1996; Rogers \& Monsell, 1995; Rubinstein, Meyer, \& Evans, 2001). This interpretation of the difference in RTs is based on assumptions about what cognitive processes are engaged in performing each type of task transition. On both types of trials, the subject must first encode the cue. If the cue is the same as that in the previous trial, the subject simply waits for the target onset and processes the target with the task set that was instantiated on the last trial. If the cue is different from that in the previous trial, the subject engages in an endogenous act of set switching before processing and responding to the target. The addition of this act of set switching increases RT.

Recently, researchers have challenged the standard interpretation of switch costs in explicit task-cuing studiesnamely, that they reflect the duration of an endogenous act of control whereby the executive switches task sets (Altmann, 2002; Logan \& Bundesen, 2003). An alternative interpretation is that switch costs can be attributed to cueencoding benefits on repetition trials, rather than endogenous set-switching processes. In this interpretation, differences between repetitions and alternations result from a faster cue-encoding process when the same cue was encoded on the previous trial.

\section{Four-Cue/Two-Task Explicit Task-Cuing Procedure}

One way that researchers have tested this alternative account is with a modified version of the explicit taskcuing procedure that involves two separate cues for each task (Logan \& Bundesen, 2003, in press; Mayr \& Kliegl, 2003). In this four-cue/two-task procedure, each task is 
cued by two different cues. For example, the two tasks might involve judgments about digits: a magnitude judgment cued with either "magnitude" or "high-low" and a parity judgment cued with either "parity" or "odd-even." This procedure generates three different task transitions: cue repetitions, where the cue and the task remain the same as those on the previous trial; task repetitions, where the cue changes but the task remains the same as that on the previous trial; and task alternations, where both the cue and the task are different from those on the previous trial.

The cue repetition and task alternation conditions represent the typical conditions in an explicit cuing procedure, and both the standard endogenous act of control account and the alternative cue repetition benefit account would predict large differences between these conditions. The task repetition condition is the diagnostic condition separating these two accounts. The standard account predicts that task repetitions will produce RTs similar to those for cue repetitions, since the task does not change from one trial to the next and, thus, no set switching is involved. The alternative account predicts that task repetitions will produce RTs similar to those for task alternations, because the cue changes from one trial to the next and, thus, cue encoding cannot benefit from repetition.

Logan and Bundesen (2003) tested these predictions, using the four-cue/two-task method. In two experiments, one using the magnitude and parity judgments described above and one using left/right and above/below judgments of spatial locations, they found that cue repetitions were much faster than task repetitions but that task repetitions were only slightly faster than task alternations. The difference was significant in only one of the two experiments. On the basis of these and other findings, they concluded that the explicit task-cuing procedure does not necessarily involve an endogenous act of set switching (see also Logan \& Bundesen, in press).

In a similar series of experiments using color and shape judgments in the four-cue/two-task procedure, Mayr and Kliegl (2003) also found a large benefit for cue repetitions over task repetitions but, in addition, found an equally large benefit for task repetitions over task alternations. On the basis of their results, they concluded that standard switch costs result from both cue switch and task switch costs, which occur during two processing stages involved in task switching. The first stage involves cue-based retrieval of the current task rules from long-term memory. The second stage involves application of those rules to the target stimulus. ${ }^{1}$

Logan and Bundesen (2003) proposed a compoundstimulus strategy to account for subjects' performance in the explicit task-cuing procedure, based on the idea that the procedure provides enough information on each trial to uniquely specify the correct response (e.g., the cue "magnitude" and the target "7" specify the "4" key). They proposed that subjects respond to combinations of cues and targets. Each task can then be performed with the same task set (i.e., encode the cue, encode the target, and retrieve the appropriate response), thus removing any need for set switching. This compound-stimulus strategy accounts for their results: Cue repetitions should be faster than task repetitions and task alternations, because the cue-encoding process is faster when the cue repeats. Task repetitions should be no faster than task alternations, because the cue changes in both cases. The present article addresses different versions of Logan and Bundesen's (2003) compound-stimulus strategy. It does not try to distinguish the compound-stimulus strategy from Mayr and Kliegl's (2003) account.

\section{Episodic Versus Semantic Compound-Stimulus Strategies}

The compound-stimulus strategy may be implemented in two ways. First, cue-target pairs may be associated with particular responses in a relatively uninterpreted manner (e.g., "squiggle1" and "squiggle2" mean "press key X"). Such a strategy would rely on episodic retrieval of past instances when specific cue-target pairs were associated with particular responses. This strategy may require several repetitions of cues and targets before reliable associations develop (Logan, 1988). In Logan and Bundesen's (2003) experiments, as in most task-switching experiments, there was a small number of target stimuli (eight digits or four spatial locations), resulting in a small number of cue-target stimulus pairs (32 or 16) that repeated throughout the experiment, making this episodic compound-stimulus strategy possible. Second, cue-target pairs may be interpreted by the subject and then used as compound cues to retrieve information from semantic memory. Subjects presumably have information about digit magnitude and parity already in semantic memory and, thus, both tasks can be accomplished with the same task set: identify the cue, identify the target, use them as a joint retrieval cue, and report what they pull out of memory (e.g., "odd-even" and "7" retrieve "odd," so the response corresponding to odd is executed). This semantic version of the compound-stimulus strategy does not require any experience with the stimuli during the experiment. Subjects can rely on preexperimental associations that are already present in semantic memory before the first trial.

In the present experiment, we contrasted the episodic and the semantic versions of the compound-stimulus strategy. We distinguished the strategies empirically by varying the number of targets the subjects experienced $(8,16,32$, or 640 targets) and, thus, the number of times a target was presented within the experiment $(80,40,20$, or 1 presentations). In order to manipulate the number of targets, we developed two tasks in which verbal stimuli and semantic category judgments were used: origin and size. The tasks were cued by name cues "origin" or "size" or by mapping cues, such as "living nonliving" or "large small”.

The episodic compound-stimulus strategy requires repeated experience with the same set of cues and targets, so the subjects should not be able to use it in the 640-target 
condition, where each target is presented only once. The subjects should be more likely to use episodic retrieval as the number of targets decreases and the number of target repetitions increases. Thus, if the subjects are only able to use an episodic compound-stimulus strategy, in the present experiment there should be an interaction between task transition condition and the number of targets. The difference between task repetitions and task alternations should be smaller the smaller the number of targets. Thus, with 640 targets, the task transition effect should resemble Mayr and Kliegl's (2003) results, suggesting that there is task switching when the task changes. However, with eight targets, the data should resemble Logan and Bundesen's (2003) results, suggesting that subjects retrieve responses from memory without task switching. The intermediate conditions should show intermediate results.

The semantic compound-stimulus strategy requires no prior experience with the targets. If subjects use this strategy, the number of targets should have no effect on the task transition conditions. Cue repetitions should be faster than task repetitions, and task repetitions should be no faster than task alternations, regardless of the number of targets.

Finally, it is possible that subjects use both episodic and semantic strategies. The semantic compound-stimulus strategy may be used early in the session when cues and targets are interpreted and used jointly to probe semantic memory. The episodic compound-stimulus strategy may be used later in the session after associations between individual cue-target pairs and responses have been established. If both episodic and semantic strategies are implemented, the number of targets should not interact with task transition conditions, but RT should be smaller overall when the episodic compound-stimulus strategy is used (8-, 16-, and 32-target conditions) than when the semantic compound-stimulus strategy is used (640-item condition), showing a speed-up in responding as memory retrieval becomes episodic (Logan, 1988).

\section{Modeling the Time Course Function}

Logan and Bundesen (2003) developed formal models that capture alternative interpretations of the time course function, the decrease in both RTs and switch costs over increasing stimulus onset asynchrony (SOA). They proposed three formal models: Model 1 assumes that switch costs arise from an endogenous act of control necessary on alternation trials (representing the modal interpretation of switch costs), Model 2 assumes that switch costs arise from a benefit for encoding the cue on repetition trials, and Model 2+1 assumes a combination of these two components. In their study, Model 1 fit the data most poorly. Model 2 provided a substantially better fit to the data. Model $2+1$ fit the data slightly better than did Model 2, but this improvement in fit was bought at the cost of unrealistically small estimates of the set-switching time and violations of the fundamental assumptions of the model (see also Logan \& Bundesen, in press). These findings support a compound-stimulus strategy account of switch costs in the explicit-cuing procedure, rather than an endogenous act of set switching.

Building on this work, we formalized three models and fit them to the time course functions in our experiment. Since Model 1 was unable to account for the data from the four-cue/two-task procedure, we did not fit that model. Model 2 instantiates the compound-stimulus strategy by assuming only a benefit for cue encoding on repetition trials. Both Models $2+1$ and Model 3 assume a cue-encoding benefit on cue repetition trials and an additional component on task alternation trials but differ in terms of when that additional component takes place. Model $2+1$ assumes an endogenous act of set switching in preparation for the upcoming task that occurs during the SOA between cue and target presentation. Model 3 assumes a benefit in target processing for repetition trials that can be modeled by allowing the time to respond to the target stimulus to vary between repetitions and alternations. Model 3 represents one possible formalization of the two-process account of Mayr and Kliegl (2003). It may also be thought of as capturing residual switch costs, because a difference in targetprocessing times for task repetitions and task alternations represents a process that cannot be initiated until the target stimulus appears.

In each of the models, the time course function is modeled in terms of the cumulative distributions of finishing times for the cue-encoding process and the setswitching process (if set switching occurs). The reduction in mean RT as a function of SOA results from the mixture of trials in which these component operations have been carried out prior to target onset and trials in which these operations must be completed following target onset, thus impacting the RT. At an SOA of zero, when the cue and the target are presented at the same time, the RT to the target includes the time to encode the cue and the time to switch task set (if set switching occurs), along with the time to process and respond to the target stimulus itself. As SOA increases, the probability that the cue is encoded and the task set is switched prior to the onset of the target increases. When SOA is long enough, cue encoding and set switching are complete before the onset of the target, and RT reflects only the time necessary to process and respond to the target. As SOA increases, the probability that RT will reflect only the time necessary to process the target increases, and thus, mean RT decreases.

The probability that cue encoding and set switching have occurred is a function of the distribution of finishing times for those processes. In the present models, we assume that these distributions are exponential. The exponential distribution is frequently used to model cognitive processes in stochastic models of RT (e.g., Townsend \& Ashby, 1983). The exponential distribution provides a simple mathematical equation with a single parameter. This parameter represents the processing rate, which is also the reciprocal of the mean of the distribution (for further justification of this assumption, see Logan \& Bundesen, 2003). 
Model 2. Model 2 assumes that the switch costs seen in the explicit task-cuing procedure result from a benefit for cue encoding on repetition trials. This assumption is implemented by allowing the mean cue-encoding times for repetitions and alternations to be separate parameters, with the constraint that mean cue-encoding time is shorter for repetitions than for alternations. Thus, mean RT on cue repetition trials can be modeled as

$$
\mathrm{RT}=\mathrm{RT}_{\text {Base }}+\mu_{\mathrm{r}} \cdot \exp \left(-\mathrm{SOA} / \mu_{\mathrm{r}}\right),
$$

and mean RT on task repetition and task alternation trials as

$$
\mathrm{RT}=\mathrm{RT}_{\text {Base }}+\mu_{\mathrm{a}} \cdot \exp \left(-\mathrm{SOA} / \mu_{\mathrm{a}}\right)
$$

In both equations, $\mathrm{RT}_{\mathrm{Base}}$ reflects the time to process the target, $\mu_{\mathrm{r}}$ and $\mu_{\mathrm{a}}$ represent the mean cue-encoding time when the cue is repeated and when the cue is not repeated, respectively, and $\mu_{\mathrm{r}}<\mu_{\mathrm{a}}$. Note that Model 2 assumes no residual switch cost.

Model 2 +1 . Model $2+1$ assumes both an endogenous act of set switching and a benefit for cue encoding. On cue repetition trials, mean RT is calculated using Equation 1. On task repetition trials, mean RT is calculated using Equation 2. On task alternation trials mean RT is

$$
\begin{array}{r}
\mathrm{RT}=\mathrm{RT}_{\mathrm{Base}}+\exp \left(-\mathrm{SOA} / \mu_{\mathrm{a}}\right) \cdot\left(\mu_{\mathrm{a}}+\mu_{\mathrm{s}}\right) \\
+\frac{1 / \mu_{\mathrm{a}}}{1 / \mu_{\mathrm{a}}-1 / \mu_{\mathrm{s}}} \cdot\left[\exp \left(-\mathrm{SOA} / \mu_{\mathrm{s}}\right)\right. \\
\left.-\exp \left(-\mathrm{SOA} / \mu_{\mathrm{a}}\right)\right] .
\end{array}
$$

where $\mathrm{RT}_{\mathrm{Base}}$ is the time necessary to process and respond to the target, which is the same in all conditions, $\mu_{\mathrm{a}}$ is the mean cue-encoding time when the cue alternates, and $\mu_{\mathrm{s}}$ is the mean set-switching time. Model 2 is nested within Model $2+1$, because if $\mu_{\mathrm{s}}$ is set to 0 , Equation 3 reduces to Equation 2. Note that Model 2+1 also assumes no residual switch cost.

Model 3. Model 3 assumes a benefit for cue encoding when the cue repeats, as well as a benefit for target processing when the task repeats. The benefit for cue encoding is implemented by allowing mean cue-encoding time for cue repetitions to be separate from mean cue-encoding time for task repetitions and task alternations, with the constraint that mean cue-encoding time is shorter for cue repetitions. The benefit for target processing is implemented by allowing $\mathrm{RT}_{\text {Base }}$ to be the same for cue repetitions and task repetitions but to differ for task alternations. Thus, mean RT on cue repetition trials can be modeled as

$$
\mathrm{RT}=\mathrm{RT}_{\text {Baserep }}+\mu_{\mathrm{r}} \cdot \exp \left(-\mathrm{SOA} / \mu_{\mathrm{r}}\right),
$$

mean RT on task repetition trials as

$$
\mathrm{RT}=\mathrm{RT}_{\text {Baserep }}+\mu_{\mathrm{a}} \cdot \exp \left(-\mathrm{SOA} / \mu_{\mathrm{a}}\right),
$$

and mean RT on task alternation trials as

$$
\mathrm{RT}=\mathrm{RT}_{\text {Basealt }}+\mu_{\mathrm{a}} \cdot \exp \left(-\mathrm{SOA} / \mu_{\mathrm{a}}\right) \text {. }
$$

$\mathrm{RT}_{\text {Baserep }}$ and $\mathrm{RT}_{\text {Basealt }}$ represent the time to process the target when the task is repeated or alternated, respec- tively, and $\mathrm{RT}_{\text {Baserep }}<\mathrm{RT}_{\text {Basealt }} . \mu_{\mathrm{r}}$ and $\mu_{\mathrm{a}}$ represent the time to encode the cue when the cue is repeated or alternated, respectively, and $\mu_{\mathrm{r}}<\mu_{\mathrm{a}}$. Model 2 is nested within Model 3, because if $\mathrm{RT}_{\text {Baserep }}$ and $\mathrm{RT}_{\text {Basealt }}$ are constrained to be equivalent, Equations 4-6 are equivalent to Equations 1 and 2.

\section{METHOD}

\section{Subjects}

The subjects were 128 students from undergraduate psychology courses, who participated for partial fulfillment of course requirements. All the subjects reported normal or corrected-to-normal vision and were native speakers of English.

\section{Design}

The basic design included one between-subjects factor and three within-subjects factors: 4 (between subjects, target set size: 8,16 , 32 , or 640$) \times 3$ (task transition condition: cue repetition, task repetition, or task alternation) $\times 10(\mathrm{SOA}: 0,100,200,300,400,500$, $600,700,800$, or 900$) \times 2$ (response-to-cue interval, RCI: 100 or 600 ). We manipulated RCI as well as SOA so that SOA would not be confounded with the interval between the response and the next target. Following previous researchers (Logan \& Bundesen, 2003; Logan \& Zbrodoff, 1982; Meiran, 1996; Meiran, Chorev, \& Sapir, 2000 ), the manipulation of RCI allowed us to interpret SOA as reflecting preparatory processes (cue encoding and set switching) and to rule out interpretations in terms of decay of past task sets (e.g., Allport, Styles, \& Hsieh, 1994; Allport \& Wylie, 2000).

\section{Apparatus and Stimuli}

Stimulus presentation and response recording were controlled by E-Prime 1.1 software running on a Dell Dimension computer with a Trinitron screen. Both targets and cues were presented in black lowercase Times New Roman font on a white background. The cues ranged from 17 to $70 \mathrm{~mm}$ in width, and the targets ranged from 10 to $63 \mathrm{~mm}$. Word height was approximately $7 \mathrm{~mm}$. The cues were presented just above the center of the display, and the targets were presented $10 \mathrm{~mm}$ below the cue. Viewing distance was not controlled. However, the subjects were positioned so as to be approximately $60 \mathrm{~cm}$ from the screen. At this distance, $1 \mathrm{~cm}$ is approximately $1^{\circ}$ of visual angle. The timing between the presentations of the cue and the target varied between 0 and $900 \mathrm{msec}$ in steps of $100 \mathrm{msec}$. Both the cue and the target remained on the screen until a response was made. Then the screen remained blank during the RCI of 100 or $600 \mathrm{msec}$.

A list of 640 target words was developed, drawn partially from Shoben, Cech, Schwanenflugel, and Sailor (1989) and supplemented by additional words chosen to complete the cells in the $2 \times 2$ crossing of origin $\times$ size tasks and to equate the cells in terms of word length and frequency. The word length ranged from 2 to 12 letters and averaged 6.46 and 6.25 for small and large items and 6.22 and 6.49 for living and nonliving items, respectively. The word frequency ranged from 0 to 117 per million and averaged 5.73 and 6.55 for small and large items and 5.62 and 6.65 for living and nonliving items, respectively (Kučera \& Francis, 1967). These values did not differ significantly. Thirty-two targets were selected from the complete list in such a way that they matched the general characteristics of word length and frequency of the full list. Each of the 32 words was used in the 32-target condition. For the 16-target condition, the 32 words were divided into two sublists. For the 8-target condition, the 32 words were divided into four sublists. The subjects in these conditions saw targets from only one of the sublists.

\section{Procedure}

A four-cue/two-task explicit task-cuing procedure was used. A cue appeared prior to the onset of each target stimulus, indicating 

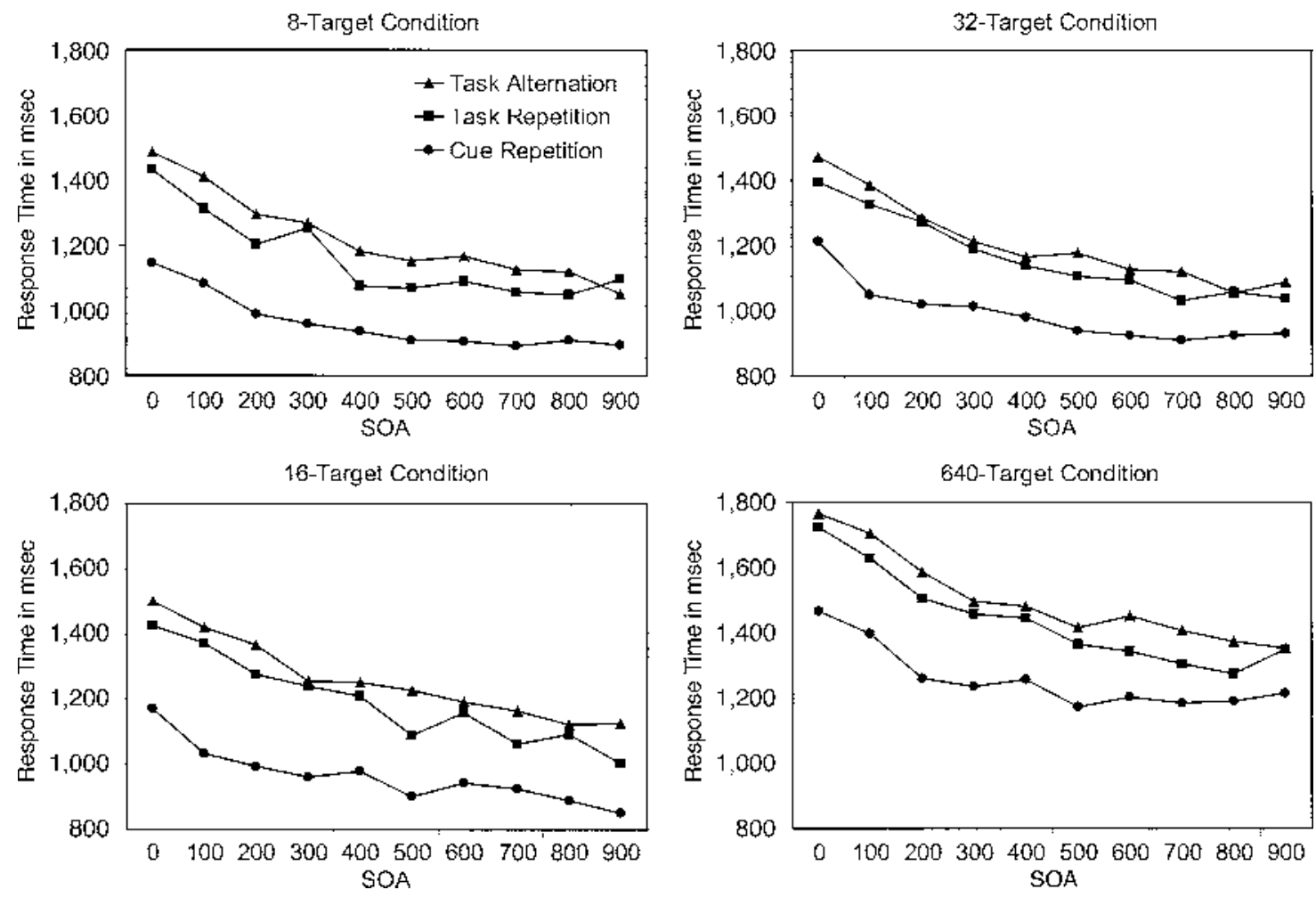

Figure 1. Mean response times as functions of stimulus onset asynchrony (SOA) in cue repetition (circles), task repetition (squares), and task alternation (triangles) conditions collapsed across response-to-cue interval for the 8-, 16-, 32-, and 640target set size conditions.

which of the two semantic judgments was to be performed. The order of presentation of the four cues was random. Following a variable SOA, the target word appeared. The SOA varied randomly within blocks and ranged from 0 to $900 \mathrm{msec}$ in 100 -msec intervals. The subjects responded manually using the "z" and "/" keys on the computer keyboard. Specific mappings of stimulus value to left- versus right-hand responses were counterbalanced across subjects. For cues that used response labels (e.g., "living nonliving" or "large small"), the order of the words in the cue was manipulated to match the spatial configuration of the appropriate response. Following the response, the cue and target disappeared from the display, which remained blank during the RCI of either 100 or $600 \mathrm{msec}$.

The subjects received written and spoken instructions describing the types of judgments that they would be performing and the responses for each task. They were told to judge size relative to "something the size of a basketball or a goose." They were told that anything of plant or animal origin should be considered living. After receiving instructions, the subjects completed four blocks of 160 trials each, with self-paced breaks provided between blocks.

\section{RESULTS}

The first response of each block was removed, since it could not be categorized into a task transition condition. Trials were then sorted into task transition conditions based on the task performed on trial $n$ and trial $n-1$, forming three conditions: cue repetition, task repetition, and task alternation. All RTs longer than $5,000 \mathrm{msec}$ or shorter than $150 \mathrm{msec}$ were removed, resulting in the re- moval of $0.9 \%$ of the data. Mean RTs were calculated for each task transition condition $\times$ timing interval. Analyses of the RT data did not differ with inclusion or exclusion of error trials, and thus, error trials were included to increase cell size for each point in the time course functions that were modeled.

\section{Standard Analyses of RT Time Course Data}

Overall, RTs were shortest in the cue repetition condition $(M=1,044 \mathrm{msec})$, followed by the task repetition and task alternation conditions $(M \mathrm{~s}=1,241$ and $1,300 \mathrm{msec}$, respectively). These results indicate that a large portion of the standard measure of switch costs (the difference between task alternations and cue repetitions) may be accounted for by cue encoding (the difference between task repetition and cue repetition, $197 \mathrm{msec}$ ), rather than by set switching (the difference between task alternation and task repetition, $59 \mathrm{msec}$ ). These results are in line with Logan and Bundesen's (2003, in press) results, where the largest portion of the switch costs can be attributed to a cue repetition benefit (but see Mayr \& Kliegl, 2003). At issue in the present experiment is whether the task transition effect interacts with the manipulation of number of targets. The pattern of large cueencoding effects and small set-switching effects held true across all four target set sizes. For the 8-, 16-, 32-, and 640-target conditions, cue-encoding benefits were 
202, 227, 175, and $181 \mathrm{msec}$, and set-switching costs were $61,70,44$, and $63 \mathrm{msec}$, respectively. The lack of an interaction between task transition condition and target set size rules out the possibility that the compoundstimulus strategy is based only on episodic memory, because an episodic memory strategy cannot account for the data in the 640-target condition. In the 640-target condition, the subjects must have used a compoundstimulus strategy based on semantic retrieval. However, the subjects were faster in the 8-, 16-, and 32-target conditions, in which the targets were repeated, than in the 640-target condition, in which all the targets were unique. Thus, when an episodic compound-stimulus strategy is available, subjects appear to use it. When the episodic strategy is not available, subjects seem to rely on the semantic strategy, if they can.

The RT data were entered into a 4 (target set size: 8 , $16,32$, or 640$) \times 3$ (task transition: cue repetition, task repetition, or task alternation) $\times 10$ (SOA: $0,100,200$, $300,400,500,600,700,800$, or $900 \mathrm{msec}) \times 2$ (RCI: 100 or $600 \mathrm{msec}$ ) mixed-factors analysis of variance (ANOVA). The main effect of target set size was significant $\left[F(3,124)=13.12, M S_{\mathrm{e}}=2,736,094.1, p<.01\right]$. Fisher's least significant difference comparisons showed that the subjects in the 640-target condition responded significantly more slowly than the subjects in the other three conditions, which did not differ from each other. The main effect of task transition condition was significant $\left[F(2,248)=393.78, M S_{\mathrm{e}}=116,461.5, p<.01\right]$. Nonorthogonal contrasts showed that cue repetitions were significantly faster than task repetitions $[F(1,124)=$ 423.3, $p<.01$ ], which were in turn significantly faster than task alternations $[F(1,124)=38.96, p<.01]$. The time course function, shown separately for each stimulus list condition in Figure 1, is captured in the main effect of SOA $\left[F(9,1116)=1,212.35, M S_{\mathrm{e}}=49,978.9, p<.01\right]$, and the task transition $\times$ SOA interaction $[F(18,2232)=$ $\left.4.91, M S_{\mathrm{e}}=49,222.5, p<.01\right]$, both of which were significant. A simple interaction analysis showed that the overall interaction resulted from a decrease in the difference between the cue repetition and the task repetition with increasing SOA $[F(9,1116)=6.44, p<.01]$ and that the difference between task repetition and task alternation did not change with SOA $[F(9,1116)=1.15, p>.1]$. Importantly for the present investigation, the three-way interaction between task transition, SOA, and target set size was not significant $[F(54,2232)=0.67]$, indicating that the time course functions were not affected by the number of target items to which the subjects were exposed. The effect of transition condition also interacted significantly with RCI $\left[F(2,248)=28.39, M S_{\mathrm{e}}=46,646.7\right.$, $p<.01]$. As RCI increased from 100 to $600 \mathrm{msec}$, RTs on cue repetition trials increased by $51 \mathrm{msec}(M \mathrm{~s}=1,019$ and $1,070 \mathrm{msec}$ ), whereas RTs on task repetition and task alternation trials decreased by $28 \mathrm{msec}(M \mathrm{~s}=1,255$ and $1,227 \mathrm{msec})$ and $26 \mathrm{msec}(M \mathrm{~s}=1,313$ and $1,287 \mathrm{msec})$, respectively. Thus, the cue-encoding benefit decreased with increasing RCI, but the set-switching cost remained relatively constant (Mayr \& Kliegl, 2003). Finally, the four-way interaction of stimulus list length, transition condition, SOA, and RCI was significant $[F(54,2232)=$ $\left.1.52, M S_{\mathrm{e}}=42,311.7, p<.05\right]$, but the pattern of this interaction does not suggest alternative interpretations of the lower order effects.

\section{Model Fits to Time Course Functions and Task Transition Effects}

We fit Models 2, 2+1, and 3 to the mean RT data for the 30 task transition $\times$ SOA conditions in each of the eight combinations of target set size and RCI, using the Solver routine in Microsoft Excel to minimize the rootmean-squared deviation (RMSD) between observed and predicted values. We fit both the mean RTs averaged across subjects for each condition and the mean RTs for each of the 32 subjects in each condition individually. In Model 2, which assumes a cue-encoding benefit for cue repetitions and no endogenous act of set switching, cue repetition was modeled with Equation 1, and task repetition and task alternation were modeled with Equation 2. Each fit involved three parameters: cue-encoding time for task repetitions $\left(\mu_{\mathrm{r}}\right)$, cue-encoding time for task alternations $\left(\mu_{\mathrm{a}}\right)$, and the time to encode and respond to the target $\left(\mathrm{RT}_{\text {Base }}\right)$. In Model $2+1$, which assumes both a cue-encoding benefit for cue repetitions and an endogenous act of set switching that occurs during the SOA, cue repetition was modeled with Equation 1, task repetition was modeled with Equation 2, and task alternation was modeled with Equation 3. There were four parameters: cue-encoding time for cue repetitions $\left(\mu_{\mathrm{r}}\right)$, cue-encoding time for task repetitions and task alternations $\left(\mu_{\mathrm{a}}\right)$, task-switching time $\left(\mu_{\mathrm{s}}\right)$, and the time to encode and respond to the target $\left(\mathrm{RT}_{\mathrm{Base}}\right)$. In Model 3, which assumes a cue-encoding benefit for cue repetitions and a target-processing advantage for task repetitions, cue repetition was modeled with Equation 4, task repetition was modeled with Equation 5, and task alternation was modeled with Equation 6 . There were four parameters: cue-encoding time for cue repetitions $\left(\mu_{\mathrm{r}}\right)$, cue-encoding time for task repetitions and task alternations $\left(\mu_{\mathrm{a}}\right)$, the time to encode and respond to the target on cue repetition and task repetition trials $\left(\mathrm{RT}_{\text {BaseRep }}\right)$, and the time to encode and respond to the target on task alternation trials $\left(\mathrm{RT}_{\mathrm{BaseAlt}}\right)$. The parameter estimates for each of the models fit to the RTs averaged across subjects, the means and standard errors of the parameter estimates for the model fits to the individual RT data, and the measures of goodness of fit (RMSD and $r$, the correlation between observed and predicted values) are given in Tables 2-5 for the 8-, 16-, 32-, and 640-target conditions, respectively. The observed RTs in each of the fitted condition are given in Table 1 . Interested readers can compare them with predicted values they calculate from the parameters in Tables 2-5.

Looking first at the fits to the average of the subjects' data, Model 2 provided reasonable fits between the observed and the predicted data for all eight combinations 
Table 1

Means (Ms) and Standard Errors (SEs) for RTs (in Milliseconds) and Response Accuracies (RAs) for Each Target Set Size Condition, Separated by RCI and Stimulus Onset Asynchrony (SOA)

\begin{tabular}{|c|c|c|c|c|c|c|c|c|c|c|c|c|c|c|c|}
\hline & \multicolumn{3}{|c|}{100 -msec RCI } & \multicolumn{3}{|c|}{ 600-msec RCI } & & \multirow{3}{*}{$\begin{array}{c}\text { SOA } \\
(\mathrm{msec})\end{array}$} & \multicolumn{3}{|c|}{ 100-msec RCI } & \multicolumn{3}{|c|}{ 600-msec RCI } \\
\hline & & \multicolumn{2}{|c|}{ RT } & \multirow[b]{2}{*}{ RA } & \multicolumn{2}{|c|}{ RT } & & & & $\mathrm{R}$ & & & RT & & \\
\hline & & $M$ & $S E$ & & $M$ & $S E$ & RA & & & $M$ & $S E$ & RA & $M$ & $S E$ & RA \\
\hline & & & $8-\mathrm{Ta}$ & ret $\mathrm{Cor}$ & dition & & & & & & $2-\mathrm{Ta}$ & get $\mathrm{Co}$ & dition & & \\
\hline Cue repetition & 0 & 1,135 & 48 & .939 & 1,158 & 53 & .942 & Cue repetition & 0 & 1,228 & 48 & .936 & 1,202 & 53 & .932 \\
\hline & 100 & 1,107 & 47 & .936 & 1,062 & 43 & .925 & & 100 & 1,042 & 47 & .956 & 1,057 & 43 & .969 \\
\hline & 200 & 1,011 & 44 & .930 & 971 & 54 & .940 & & 200 & 954 & 44 & .932 & 1,088 & 54 & .937 \\
\hline & 300 & 901 & 52 & .928 & 1,021 & 57 & .927 & & 300 & 1,007 & 52 & .940 & 1,019 & 57 & .962 \\
\hline & 400 & 891 & 55 & .937 & 981 & 48 & .945 & & 400 & 966 & 55 & .956 & 996 & 48 & .915 \\
\hline & 500 & 875 & 43 & .954 & 947 & 45 & .938 & & 500 & 937 & 43 & .953 & 945 & 45 & .950 \\
\hline & 600 & 882 & 44 & .981 & 932 & 57 & .916 & & 600 & 841 & 44 & .919 & 1,008 & 57 & .970 \\
\hline & 700 & 889 & 41 & .937 & 893 & 59 & .920 & & 700 & 863 & 41 & .948 & 958 & 59 & .930 \\
\hline & 800 & 875 & 41 & .930 & 945 & 54 & .925 & & 800 & 875 & 41 & .926 & 975 & 54 & .934 \\
\hline & 900 & 841 & 46 & .936 & 950 & 53 & .923 & & 900 & 909 & 46 & .960 & 952 & 53 & .964 \\
\hline Task repetition & 0 & 1,459 & 60 & .945 & 1,406 & 57 & .920 & Task repetition & 0 & 1,429 & 60 & .954 & 1,361 & 57 & .937 \\
\hline & 100 & 1,337 & 60 & .900 & 1,292 & 64 & .959 & & 100 & 1,346 & 60 & .945 & 1,309 & 64 & .936 \\
\hline & 200 & 1,216 & 61 & .957 & 1,192 & 58 & .936 & & 200 & 1,287 & 61 & .917 & 1,257 & 58 & .945 \\
\hline & 300 & 1,251 & 63 & .959 & 1,255 & 62 & .915 & & 300 & 1,213 & 63 & .942 & 1,169 & 62 & .958 \\
\hline & 400 & 1,115 & 58 & .942 & 1,039 & 59 & .950 & & 400 & 1,132 & 58 & .943 & 1,146 & 59 & .940 \\
\hline & 500 & 1,128 & 59 & .901 & 1,015 & 54 & .947 & & 500 & 1,119 & 59 & .948 & 1,097 & 54 & .930 \\
\hline & 600 & 1,086 & 61 & .932 & 1,098 & 65 & .955 & & 600 & 1,090 & 61 & .946 & 1,102 & 65 & .949 \\
\hline & 700 & 1,051 & 64 & .940 & 1,066 & 53 & .925 & & 700 & 1,097 & 64 & .951 & 966 & 53 & .944 \\
\hline & 800 & 1,028 & 56 & .952 & 1,069 & 52 & .933 & & 800 & 1,039 & 56 & .967 & 1,078 & 52 & .955 \\
\hline & 900 & 1,086 & 60 & .890 & 1,110 & 57 & .943 & & 900 & 1,077 & 60 & .958 & 997 & 57 & .921 \\
\hline Task alternation & 0 & 1,499 & 53 & .920 & 1,469 & 55 & .918 & Task alternation & 0 & 1,529 & 53 & .925 & 1,417 & 55 & .935 \\
\hline & 100 & 1,415 & 58 & .914 & 1,406 & 55 & .915 & & 100 & 1,426 & 58 & .928 & 1,346 & 55 & .910 \\
\hline & 200 & 1,316 & 57 & .915 & 1,275 & 54 & .929 & & 200 & 1,318 & 57 & .932 & 1,251 & 54 & .939 \\
\hline & 300 & 1,265 & 45 & .899 & 1,275 & 55 & .913 & & 300 & 1,222 & 45 & .922 & 1,209 & 55 & .914 \\
\hline & 400 & 1,201 & 56 & .934 & 1,163 & 59 & .915 & & 400 & 1,170 & 56 & .922 & 1,165 & 59 & .934 \\
\hline & 500 & 1,138 & 49 & .916 & 1,167 & 53 & .929 & & 500 & 1,207 & 49 & .919 & 1,151 & 53 & .908 \\
\hline & 600 & 1,166 & 58 & .909 & 1,168 & 54 & .909 & & 600 & 1,161 & 58 & .927 & 1,091 & 54 & .919 \\
\hline & 700 & 1,135 & 51 & .918 & 1,120 & 51 & .909 & & 700 & 1,124 & 51 & .920 & 1,118 & 51 & .942 \\
\hline & 800 & 1,084 & 51 & .926 & 1,158 & 53 & .924 & & 800 & 1,066 & 51 & .931 & 1,047 & 53 & .911 \\
\hline & 900 & 1,061 & 49 & .920 & 1,044 & 50 & .921 & & 900 & 1,097 & 50 & .932 & 1,080 & 50 & .915 \\
\hline & & & 6-Ta & get $\mathrm{Co}$ & dition & & & & & & 40 & $\mathrm{tCr}$ & adition & & \\
\hline Cue repetition & 0 & 1,111 & 48 & .965 & 1,232 & 53 & .953 & Cue repetition & 0 & 1,417 & 48 & .931 & 1,515 & 53 & .913 \\
\hline & 100 & 1,015 & 47 & .945 & 1,056 & 43 & .927 & & 100 & 1,335 & 47 & .930 & 1,458 & 43 & .959 \\
\hline & 200 & 959 & 44 & .931 & 1,028 & 54 & .940 & & 200 & 1,273 & 44 & .899 & 1,244 & 54 & .964 \\
\hline & 300 & 966 & 52 & .951 & 958 & 57 & .914 & & 300 & 1,229 & 52 & .939 & 1,246 & 57 & .866 \\
\hline & 400 & 981 & 55 & .925 & 977 & 48 & .905 & & 400 & 1,271 & 55 & .949 & 1,241 & 48 & .923 \\
\hline & 500 & 877 & 43 & .907 & 928 & 45 & .927 & & 500 & 1,170 & 43 & .957 & 1,173 & 45 & .948 \\
\hline & 600 & 926 & 44 & .95 & 964 & 57 & .950 & & 600 & 1,166 & 44 & .936 & 1,240 & 57 & .922 \\
\hline & 700 & 831 & 41 & .937 & 1,023 & 59 & .892 & & 700 & 1,185 & 41 & .952 & 1,184 & 59 & .912 \\
\hline & 800 & 851 & 41 & .937 & 927 & 54 & .939 & & 800 & 1,188 & 41 & .925 & 1,191 & 54 & .918 \\
\hline & 900 & 813 & 46 & .924 & 891 & 53 & .943 & & 900 & 1,154 & 46 & .914 & 1,274 & 53 & .935 \\
\hline Task repetition & 0 & 1,472 & 60 & .904 & 1,377 & 57 & .941 & Task repetition & 0 & 1,692 & 60 & .974 & 1,753 & 57 & .927 \\
\hline & 100 & 1,395 & 60 & .949 & 1,349 & 64 & .896 & & 100 & 1,685 & 60 & .953 & 1,570 & 64 & .955 \\
\hline & 200 & 1,331 & 61 & .890 & 1,224 & 58 & .933 & & 200 & 1,514 & 61 & .946 & 1,492 & 58 & .901 \\
\hline & 300 & 1,217 & 63 & .946 & 1,264 & 62 & .944 & & 300 & 1,577 & 63 & .924 & 1,338 & 62 & .915 \\
\hline & 400 & 1,191 & 58 & .90 & 1,227 & 59 & .9 & & 400 & 1,466 & 58 & .933 & 1,423 & 59 & .951 \\
\hline & 500 & 1,103 & 59 & .939 & 1,077 & 54 & .935 & & 500 & 1,429 & 59 & .937 & 1,297 & 54 & .924 \\
\hline & 600 & 1,192 & 61 & .928 & 1,127 & 65 & .924 & & 600 & 1,390 & 61 & .920 & 1,297 & 65 & .925 \\
\hline & 700 & 1,010 & 64 & .956 & 1,115 & 53 & .916 & & 700 & 1,278 & 64 & .942 & 1,332 & 53 & .937 \\
\hline & 800 & 1,057 & 56 & .921 & 1,130 & 52 & .938 & & 800 & 1,295 & 56 & .933 & 1,253 & 52 & .924 \\
\hline & 900 & 1,411 & 60 & .934 & 1,069 & 57 & .927 & & 900 & 1,372 & 60 & .907 & 1,328 & 57 & .928 \\
\hline Task alternation & 0 & 1,538 & 53 & .903 & 1,461 & 55 & .904 & Task alternation & 0 & 1,781 & 53 & .926 & 1,750 & 55 & .911 \\
\hline & 100 & 1,450 & 58 & .940 & 1,393 & 55 & .911 & & 100 & 1,803 & 58 & .903 & 1,606 & 55 & .908 \\
\hline & 200 & 1,402 & 57 & .928 & 1,328 & 54 & .916 & & 200 & 1,613 & 57 & .917 & 1,555 & 54 & .913 \\
\hline & 300 & 1,213 & 45 & .918 & 1,299 & 55 & .908 & & 300 & 1,515 & 45 & .942 & 1,478 & 55 & .926 \\
\hline & 400 & 1,290 & 56 & .909 & 1,213 & 59 & .910 & & 400 & 1,453 & 56 & .921 & 1,508 & 59 & .926 \\
\hline & 500 & 1,241 & 49 & .925 & 1,213 & 53 & .930 & & 500 & 1,428 & 49 & .933 & 1,400 & 53 & .924 \\
\hline & 600 & 1,188 & 58 & .894 & 1,197 & 54 & .921 & & 600 & 1,488 & 58 & .907 & 1,411 & 54 & .920 \\
\hline & 700 & 1,198 & 51 & .906 & 1,130 & 51 & .911 & & 700 & 1,404 & 51 & .917 & 1,410 & 51 & .930 \\
\hline & 800 & 1,118 & 51 & .920 & 1,127 & 53 & .916 & & 800 & 1,353 & 51 & .942 & 1,391 & 53 & .943 \\
\hline & 900 & 1,151 & 50 & .912 & 1,103 & 50 & .923 & & 900 & 1,312 & 50 & .911 & 1,390 & 50 & .917 \\
\hline
\end{tabular}


Table 2

Values of the Best-Fitting Parameters and Measures of Goodness of Fit for Fits of Model 2, Model 2+1, and Model 3 to the Data Averaged Across Subjects, Means, and Standard Errors (SEs) of Values of Best-Fitting Parameters, and Measures of Goodness of Fit for Fits of the Same Models to 32 Individual Subjects in the 8-Target Condition

\begin{tabular}{lrrrrrrrr}
\hline & \multicolumn{7}{c}{ Model 2 } \\
\cline { 2 - 8 } RCI 100 & $\mu_{\mathrm{r}}$ & $\mu_{\mathrm{a}}$ & $\mu_{\mathrm{s}}$ & $\mathrm{RT}_{\text {BaseRep }}$ & $\mathrm{RT}_{\text {Base }}$ & $\mathrm{RT}_{\text {BaseAlt }}$ & $r$ & RMSD \\
\hline Average & 262 & 615 & & & 868 & & .973 & 41 \\
Mean & 272 & 630 & & & 846 & .678 & 187 \\
$S E$ & 31 & 41 & & & 32 & .028 & 11
\end{tabular}

Model $2+1$

\begin{tabular}{lrrrrrrrr} 
& $\mu_{\mathrm{r}}$ & $\mu_{\mathrm{a}}$ & \multicolumn{1}{c}{$\mu_{\mathrm{s}}$} & $\mathrm{RT}_{\text {BaseRep }}$ & $\mathrm{RT}_{\text {Base }}$ & $\mathrm{RT}_{\text {BaseAlt }}$ & $r$ & $\mathrm{RMSD}$ \\
\hline Average & 257 & 585 & 67 & & 872 & & .978 & 37 \\
Mean & 268 & 583 & 102 & & 849 & & .696 & 182 \\
$S E$ & 30 & 39 & 19 & & 32 & & .026 & 10
\end{tabular}

Model 3

\begin{tabular}{lrrrrrrrr} 
& $\mu_{\mathrm{r}}$ & $\mu_{\mathrm{a}}$ & $\mu_{\mathrm{s}}$ & $\mathrm{RT}_{\text {BaseRep }}$ & $\mathrm{RT}_{\text {Base }}$ & $\mathrm{RT}_{\text {BaseAlt }}$ & $r$ & $\mathrm{RMSD}$ \\
\hline Average & 268 & 584 & & 864 & & 924 & .983 & 33 \\
Mean & 295 & 611 & & 832 & & 890 & .709 & 180 \\
$S E$ & 31 & 40 & & 32 & & 34 & .025 & 10
\end{tabular}

Model 2

\begin{tabular}{lrrrrrrrr}
\cline { 2 - 7 } RCI 600 & $\mu_{\mathrm{r}}$ & $\mu_{\mathrm{a}}$ & $\mu_{\mathrm{s}}$ & $\mathrm{RT}_{\text {BaseRep }}$ & $\mathrm{RT}_{\text {Base }}$ & $\mathrm{RT}_{\text {BaseAlt }}$ & $r$ & $\mathrm{RMSD}$ \\
\hline Average & 178 & 486 & & & 955 & & .932 & 54 \\
Mean & 230 & 538 & & & 902 & & .577 & 201 \\
$S E$ & 43 & 44 & & & 52 & & .027 & 10
\end{tabular}

Model 2+1

\begin{tabular}{lrrrrrrrr} 
& $\mu_{\mathrm{r}}$ & $\mu_{\mathrm{a}}$ & $\mu_{\mathrm{s}}$ & $\mathrm{RT}_{\text {BaseRep }}$ & $\mathrm{RT}_{\text {Base }}$ & $\mathrm{RT}_{\text {BaseAlt }}$ & $r$ & $\mathrm{RMSD}$ \\
\hline Average & 171 & 440 & 106 & & 960 & & .948 & 48 \\
Mean & 223 & 476 & 122 & & 909 & & .577 & 196 \\
$S E$ & 41 & 45 & 24 & & 50 & & .027 & 10
\end{tabular}

Model 3

\begin{tabular}{lrrrrrrrr} 
& $\mu_{\mathrm{r}}$ & $\mu_{\mathrm{a}}$ & $\mu_{\mathrm{s}}$ & $\mathrm{RT}_{\text {BaseRep }}$ & $\mathrm{RT}_{\text {Base }}$ & $\mathrm{RT}_{\text {BaseAlt }}$ & $r$ & $\mathrm{RMSD}$ \\
\hline Average & 188 & 445 & & 948 & & 1,027 & .958 & 43 \\
Mean & 245 & 499 & & 891 & 970 & .614 & 194 \\
$S E$ & 45 & 47 & & 53 & 60 & .026 & 10 \\
\hline
\end{tabular}

Note-RCI, response-to-cue interval.

of target set size and RCI. Averaged across target set size and RCI, the mean $r$ value was .954 and the mean RMSD was $48 \mathrm{msec}$. This result reflects the fact that the cueencoding benefit is considerably larger than the setswitching cost and is consistent with the compoundstimulus strategy. Model $2+1$ fit the data slightly better than did Model 2. Averaged across target set size and $\mathrm{RCI}$, the mean $r$ value was .962 , and the mean RMSD was $44 \mathrm{msec}$. Since Model 2 is nested within Model $2+1$, the improvement in goodness of fit can be assessed by statistically comparing the correlation coefficients. Comparisons of goodness of fit showed modest improvements of Model $2+1$ over Model 2 that did not reach significance in all combinations of target set size and RCI [8-target condition, $F_{\mathrm{S}}(1,26)=6.11$ and $8.88, p<.05$; 16 -target condition, $F(1,26)=6.89, p<.05$ and $F(1,26)=3.54, p>.05 ; 32$-target condition, $F(1,26)=$ $5.19, p<.05$ and $F(1,26)=3.79, p>.05 ; 640$-target conditions, $F \mathrm{~s}(1,26)=5.62$ and $4.91, p<.05$, for short and long RCI conditions, respectively].
Model 3 fit the data slightly better than did Model 2. Averaged across target set size and RCI, the mean $r$ value was .969 , and the mean RMSD was 39 msec. Model 2 is nested in Model 3, so the improvement in goodness of fit can be tested statistically. The improvements in goodness of fit over Model 2 were significant for all target set size $X$ RCI conditions [8-target condition, $F_{\mathrm{S}}(1,26)=14.45$ and $17.42, p \mathrm{~s}<.05 ; 16$-target condition, $F \mathrm{~s}(1,26)=20.47$ and $11.31, p \mathrm{~s}<.05 ; 32$-target condition, $F \mathrm{~s}(1,26)=10.52$ and $11.63, p \mathrm{~s}<.05 ; 640$-target conditions, $F \mathrm{~s}(1,26)=5.73$ and 18.01, $p \mathrm{~s}<.05$, for short and long RCI conditions, respectively]. Whereas Model 3 provided significantly better fits to the data than did Model 2, the parameters, $\mathrm{RT}_{\text {BaseRep }}$ and $\mathrm{RT}_{\text {BaseAlt }}$, which allow for residual switch costs in Model 3, differed by amounts that were relatively small, as compared with the differences between $\mu_{\mathrm{r}}$ and $\mu_{\mathrm{a}}$.

The models did not fit the individual subject data as well as the average data, but the quantitative relationships among the three models were the same as those for 
Table 3

Values of the Best-Fitting Parameters and Measures of Goodness of Fit for Fits of Model 2, Model 2+1, and Model 3 to the Data Averaged Across Subjects, Means, and Standard Errors (SEs) of Values of Best-Fitting Parameters, and Measures of Goodness of Fit for Fits of the Same Models to 32 Individual Subjects in the 16-Target Condition

\begin{tabular}{lrrrrrrrr}
\hline & \multicolumn{7}{c}{ Model 2 } \\
\cline { 2 - 8 } RCI 100 & $\mu_{\mathrm{r}}$ & $\mu_{\mathrm{a}}$ & $\mu_{\mathrm{s}}$ & $\mathrm{RT}_{\text {BaseRep }}$ & $\mathrm{RT}_{\text {Base }}$ & $\mathrm{RT}_{\text {BaseAlt }}$ & $r$ & RMSD \\
\hline Average & 253 & 665 & & & 862 & & .958 & 57 \\
Mean & 270 & 690 & & & 834 & & .697 & 201 \\
$S E$ & 33 & 42 & & & 33 & & .022 & 13
\end{tabular}

\begin{tabular}{lrrrrrrrr} 
& \multicolumn{8}{c}{ Model 2+1 } \\
\cline { 2 - 8 } & $\mu_{\mathrm{r}}$ & $\mu_{\mathrm{a}}$ & \multicolumn{1}{c}{$\mu_{\mathrm{s}}$} & $\mathrm{RT}_{\text {BaseRep }}$ & $\mathrm{RT}_{\text {Base }}$ & $\mathrm{RT}_{\text {BaseAlt }}$ & $r$ & $\mathrm{RMSD}$ \\
Average & 249 & 626 & 95 & & 865 & & .967 & 51 \\
Mean & 260 & 627 & 126 & 842 & .720 & 194 \\
$S E$ & 30 & 39 & 25 & 32 & .022 & 12
\end{tabular}

\begin{tabular}{lrrrrrrrr} 
& \multicolumn{8}{c}{ Model 3 } \\
\cline { 2 - 8 } & $\mu_{\mathrm{r}}$ & $\mu_{\mathrm{a}}$ & $\mu_{\mathrm{s}}$ & $\mathrm{RT}_{\text {BaseRep }}$ & $\mathrm{RT}_{\text {Base }}$ & $\mathrm{RT}_{\text {BaseAlt }}$ & $r$ & $\mathrm{RMSD}$ \\
Average & 263 & 619 & & 855 & & 947 & .977 & 42 \\
Mean & 280 & 643 & & 826 & & 917 & .726 & 193 \\
$S E$ & 34 & 42 & 34 & & 41 & .022 & 12
\end{tabular}

Model 2

\begin{tabular}{lrrrrrrrr}
\cline { 2 - 7 } RCI 600 & $\mu_{\mathrm{r}}$ & $\mu_{\mathrm{a}}$ & $\mu_{\mathrm{s}}$ & $\mathrm{RT}_{\text {BaseRep }}$ & $\mathrm{RT}_{\text {Base }}$ & $\mathrm{RT}_{\text {BaseAlt }}$ & $r$ & $\mathrm{RMSD}$ \\
\hline Average & 197 & 519 & & & 962 & & .948 & 48 \\
Mean & 225 & 547 & & & 930 & & .592 & 201 \\
$S E$ & 30 & 36 & & & 37 & & .024 & 13
\end{tabular}

Model $2+1$

\begin{tabular}{lrrrrrrrr} 
& $\mu_{\mathrm{r}}$ & $\mu_{\mathrm{a}}$ & \multicolumn{1}{c}{$\mu_{\mathrm{s}}$} & $\mathrm{RT}_{\text {BaseRep }}$ & $\mathrm{RT}_{\text {Base }}$ & $\mathrm{RT}_{\text {BaseAlt }}$ & \multicolumn{1}{c}{} & $\mathrm{RMSD}$ \\
\cline { 2 - 9 } Average & 193 & 493 & 62 & & 965 & & .954 & 46 \\
Mean & 221 & 483 & 117 & & 934 & & .592 & 197 \\
$S E$ & 30 & 43 & 25 & & 38 & & .024 & 12 \\
& & & & & Model 3 & & & \\
\cline { 2 - 9 } & $\mu_{\mathrm{r}}$ & $\mu_{\mathrm{a}}$ & $\mu_{\mathrm{s}}$ & $\mathrm{RT}_{\text {BaseRep }}$ & $\mathrm{RT}_{\text {Base }}$ & $\mathrm{RT}_{\text {BaseAlt }}$ & $r$ & $\mathrm{RMSD}$ \\
Average & 203 & 485 & & 958 & & 1,020 & .963 & 41 \\
Mean & 235 & 508 & & 923 & & 984 & .628 & 195 \\
$S E$ & 30 & 43 & & 38 & & 46 & .021 & 12 \\
\hline
\end{tabular}

Note-RCI, response-to-cue interval.

the fits to the average data. For Model 2, the mean $r$ value was .63, and the mean RMSD was $198 \mathrm{msec}$, averaged over subjects, target set size, and RCI. For Model $2+1$, the corresponding means were .64 and $193 \mathrm{msec}$. For Model 3, the corresponding means were .66 and $191 \mathrm{msec}$. The fit of Model 2 can again be directly compared with those of the other two models in which it is nested. The top panel in Table 6 gives the number of subjects who showed significant increases in model fit from Model 2 to the other models. At the level of individual subjects, very few subjects showed a significant improvement in fit between Model 2 and Models $2+1$ and 3. ${ }^{2}$

Models $2+1$ and 3 cannot be compared directly, since the models are not nested. However, we can compare the number of subjects for which the $r$ value for one model exceeded that for the other, using the normal approximation to the binomial distribution. Correlation coefficients were larger for Model 3 than for Model $2+1$ in a significant number of subjects in all conditions, except for the 16-target, 100-msec RCI and the 32-target, 600msec RCI conditions. This finding indicates that the small differences between task repetition and task alternation conditions are best accounted for by a process that occurs following the onset of the target, rather than during the SOA.

Whereas the overall fits for all the models were significantly poorer when fit to the individual subject data than when fit to the average means across subjects, the parameter estimates were similar. Most of the parameter estimates for the fits to average means were within the $95 \%$ confidence intervals of the mean parameter estimates of the fits to individual subject data. However, for Model $2+1$, the estimates of $\mu_{\mathrm{s}}$ based on the average means across subjects were below the $95 \%$ confidence intervals for the mean parameter estimates of the fits to individual subject data for the 16-target condition at the 600-msec RCI and the 32-target condition at both RCIs.

\section{Ancillary RT Analyses}

In addition to the primary analyses of the time course functions, the experimental design allows us to consider several other factors that may impact subjects' respond- 
Table 4

Values of the Best-Fitting Parameters and Measures of Goodness of Fit for Fits of Model 2, Model 2+1, and Model 3 to the Data Averaged Across Subjects, Means, and Standard Errors (SEs) of Values of Best-Fitting Parameters, and Measures of Goodness of Fit for Fits of the Same Models to 32 Individual Subjects in the 32-Target Condition

\begin{tabular}{lrrrrrrrr}
\hline & \multicolumn{7}{c}{ Model 2 } \\
\cline { 2 - 8 } RCI 100 & $\mu_{\mathrm{r}}$ & $\mu_{\mathrm{a}}$ & $\mu_{\mathrm{s}}$ & $\mathrm{RT}_{\text {BaseRep }}$ & $\mathrm{RT}_{\text {Base }}$ & $\mathrm{RT}_{\text {BaseAlt }}$ & $r$ & $\mathrm{RMSD}$ \\
\hline Average & 262 & 595 & & & 890 & & .968 & 43 \\
Mean & 308 & 649 & & & 835 & .707 & 172 \\
$S E$ & 50 & 54 & & & 4 & & .024 & 12
\end{tabular}

\begin{tabular}{lrrrrrrrr} 
& \multicolumn{8}{c}{ Model 2+1 } \\
\cline { 2 - 9 } & $\mu_{\mathrm{r}}$ & $\mu_{\mathrm{a}}$ & $\mu_{\mathrm{s}}$ & $\mathrm{RT}_{\text {BaseRep }}$ & $\mathrm{RT}_{\text {Base }}$ & $\mathrm{RT}_{\text {BaseAlt }}$ & $r$ & RMSD \\
Average & 256 & 565 & 66 & & 895 & .973 & 40 \\
Mean & 302 & 600 & 101 & & 841 & .724 & 168 \\
$S E$ & 50 & 57 & 16 & 46 & .024 & 12
\end{tabular}

\begin{tabular}{lrrrrrrrr} 
& \multicolumn{8}{c}{ Model 3 } \\
\cline { 2 - 8 } & $\mu_{\mathrm{r}}$ & $\mu_{\mathrm{a}}$ & $\mu_{\mathrm{s}}$ & $\mathrm{RT}_{\text {BaseRep }}$ & $\mathrm{RT}_{\text {Base }}$ & $\mathrm{RT}_{\text {BaseAlt }}$ & $r$ & $\mathrm{RMSD}$ \\
Average & 268 & 566 & & 886 & & 942 & .977 & 36 \\
Mean & 318 & 622 & & 829 & & 884 & .727 & 167 \\
$S E$ & 48 & 55 & & 45 & & 49 & .024 & 12
\end{tabular}

Model 2

\begin{tabular}{lrrrrrrrr}
\cline { 2 - 7 } RCI 600 & $\mu_{\mathrm{r}}$ & $\mu_{\mathrm{a}}$ & $\mu_{\mathrm{s}}$ & $\mathrm{RT}_{\text {BaseRep }}$ & $\mathrm{RT}_{\text {Base }}$ & $\mathrm{RT}_{\text {BaseAlt }}$ & $r$ & $\mathrm{RMSD}$ \\
\hline Average & 210 & 444 & & & 969 & & .968 & 32 \\
Mean & 268 & 493 & & & 917 & & .604 & 175 \\
$S E$ & 40 & 43 & & & 37 & & .030 & 11
\end{tabular}

Model $2+1$

\begin{tabular}{|c|c|c|c|c|c|c|c|c|}
\hline & $\mu_{\mathrm{r}}$ & $\mu_{\mathrm{a}}$ & $\mu_{\mathrm{s}}$ & $\mathrm{RT}_{\text {BaseRep }}$ & $\mathrm{RT}_{\text {Base }}$ & $\mathrm{RT}_{\text {BaseAlt }}$ & $r$ & RMSD \\
\hline Average & 206 & 425 & 46 & & 971 & & .971 & 30 \\
\hline Mean & 263 & 440 & 101 & & 921 & & .604 & 171 \\
\hline \multirow[t]{3}{*}{$S E$} & 40 & 47 & 21 & & 37 & & .030 & 11 \\
\hline & \multicolumn{8}{|c|}{ Model 3} \\
\hline & $\mu_{\mathrm{r}}$ & $\mu_{\mathrm{a}}$ & $\mu_{\mathrm{s}}$ & $\mathrm{RT}_{\text {BaseRep }}$ & $\mathrm{RT}_{\text {Base }}$ & $\mathrm{RT}_{\text {BaseAlt }}$ & $r$ & RMSD \\
\hline Average & 219 & 426 & & 962 & & 1,003 & .977 & 27 \\
\hline Mean & 282 & 479 & & 905 & & 948 & .628 & 171 \\
\hline$S E$ & 41 & 45 & & 36 & & 42 & .029 & 11 \\
\hline
\end{tabular}

Note-RCI, response-to-cue interval.

ing differently on different types of task transitions. The cues used in the present experiment were either name cues (i.e., "origin" and "size") or mapping cues (i.e., "living nonliving" and "large small"). Mayr and Kliegl (2000) demonstrated that name cues result in larger switch costs than do mapping cues that directly indicate the category-to-response mapping. We considered the effect of name versus mapping cues in a 4 (target set size: $8,16,32$, or 640$) \times 3$ (task transition: cue repetition, task repetition, or task alternation) $\times 2$ (cue type: name or mapping) mixed-factors ANOVA, collapsing across SOA and RCI in order to have an adequate number of data points in each cell. The interaction of task transition and cue type was significant $[F(2,248)=4.15$, $\left.M S_{\mathrm{e}}=5,224.5, p<.05\right]$. Planned comparisons of name and mapping cues showed that RTs were significantly shorter for mapping cues than for name cues, by $40 \mathrm{msec}$ for task repetitions and $27 \mathrm{msec}$ for task alternations. For the cue repetitions, mapping cues were only $4 \mathrm{msec}$ faster than name cues, which was not significant. This result suggests that the difference between name and mapping cues acts at the level of cue encoding, rather than changes in task.

The responses in this experiment were bivalent, with the same two keys mapped to responses for both tasks. Consequently, it was possible to analyze the effects of response repetitions on task transitions. Previous researchers have shown that response repetitions benefit performance when a task repeats but interfere when the task switches (Mayr \& Klieg1, 2003; Rogers \& Monsell, 1995). We analyzed response repetitions in a 4 (target set size: $8,16,32$, or 640$) \times 3$ (task transition: cue repetition, task repetition, or task alternation) $\times 2$ (response transition: repetition or alternation) mixed-factors ANOVA, collapsing across SOA and RCI. The interaction of task transition and response transition was significant $\left[F(2,248)=28.73, M S_{\mathrm{e}}=4,599.6, p<.01\right]$. Planned comparisons of the response transition effect showed that, as compared with response alternations, RTs were 54 msec shorter on response repetitions for cue 
Table 5

Values of the Best-Fitting Parameters and Measures of Goodness of Fit for Fits of

Model 2, Model 2+1, and Model 3 to the Data Averaged Across Subjects, Means, and Standard Errors (SEs) of Values of Best-Fitting Parameters, and Measures of Goodness of Fit for Fits of the Same Models to 32 Individual Subjects in the 640-Target Condition

\begin{tabular}{lrrrrrrrr}
\hline & \multicolumn{7}{c}{ Model 2 } \\
\cline { 2 - 8 } RCI 100 & \multicolumn{1}{c}{$\mu_{\mathrm{r}}$} & $\mu_{\mathrm{a}}$ & $\mu_{\mathrm{s}}$ & $\mathrm{RT}_{\text {BaseRep }}$ & $\mathrm{RT}_{\text {Base }}$ & $\mathrm{RT}_{\text {BaseAlt }}$ & $r$ & $\mathrm{RMSD}$ \\
\hline Average & 244 & 605 & & & 1,170 & & .967 & 45 \\
Mean & 262 & 635 & & & 1,140 & .639 & 212 \\
$S E$ & 33 & 27 & & & 39 & .024 & 10
\end{tabular}

Model $2+1$

\begin{tabular}{|c|c|c|c|c|c|c|c|c|}
\hline & $\mu_{\mathrm{r}}$ & $\mu_{\mathrm{a}}$ & $\mu_{\mathrm{s}}$ & $\mathrm{RT}_{\text {BaseRep }}$ & $\mathrm{RT}_{\text {Base }}$ & $\mathrm{RT}_{\text {BaseAlt }}$ & $r$ & RMSD \\
\hline Average & 237 & 572 & 72 & & 1,175 & & .973 & 41 \\
\hline Mean & 253 & 581 & 106 & & 1,146 & & .661 & 206 \\
\hline \multirow[t]{3}{*}{$S E$} & 33 & 29 & 24 & & 39 & & .025 & 10 \\
\hline & \multicolumn{8}{|c|}{ Model 3} \\
\hline & $\mu_{\mathrm{r}}$ & $\mu_{\mathrm{a}}$ & $\mu_{\mathrm{s}}$ & $\mathrm{RT}_{\text {BaseRep }}$ & $\mathrm{RT}_{\text {Base }}$ & $\mathrm{RT}_{\text {BaseAlt }}$ & $r$ & RMSD \\
\hline Average & 251 & 582 & & 1,166 & & 1,212 & .973 & 41 \\
\hline Mean & 266 & 610 & & 1,136 & & 1,184 & .663 & 205 \\
\hline$S E$ & 34 & 28 & & 39 & & 46 & .025 & 10 \\
\hline
\end{tabular}

Model 2

\begin{tabular}{lrrrrrrrr}
\cline { 2 - 7 } RCI 600 & $\mu_{\mathrm{r}}$ & $\mu_{\mathrm{a}}$ & $\mu_{\mathrm{s}}$ & $\mathrm{RT}_{\text {BaseRep }}$ & $\mathrm{RT}_{\text {Base }}$ & $\mathrm{RT}_{\text {BaseAlt }}$ & $r$ & $\mathrm{RMSD}$ \\
\hline Average & 245 & 491 & & & 1,213 & & .921 & 60 \\
Mean & 280 & 544 & & & 1,164 & & .548 & 230 \\
$S E$ & 38 & 36 & & & 33 & & .021 & 12
\end{tabular}

Model $2+1$

\begin{tabular}{|c|c|c|c|c|c|c|c|c|}
\hline & $\mu_{\mathrm{r}}$ & $\mu_{\mathrm{a}}$ & $\mu_{\mathrm{s}}$ & $\mathrm{RI}_{\text {BaseRep }}$ & $\mathrm{RT}_{\text {Base }}$ & $\mathrm{KI}_{\text {BaseAlt }}$ & $r$ & RMSD \\
\hline Average & 240 & 452 & 94 & & 1,217 & & .932 & 55 \\
\hline Mean & 281 & 482 & 127 & & 1,166 & & .548 & 224 \\
\hline \multirow[t]{3}{*}{$S E$} & 37 & 39 & 29 & & 33 & & .021 & 11 \\
\hline & \multicolumn{8}{|c|}{ Model 3} \\
\hline & $\mu_{\mathrm{r}}$ & $\mu_{\mathrm{a}}$ & $\mu_{\mathrm{s}}$ & $\mathrm{RT}_{\text {BaseRep }}$ & $\mathrm{RT}_{\text {Base }}$ & $\mathrm{RT}_{\text {BaseAlt }}$ & $r$ & RMSD \\
\hline Average & 260 & 450 & & 1,202 & & 1,289 & .951 & 47 \\
\hline Mean & 294 & 504 & & 1,155 & & 1,238 & .585 & 221 \\
\hline$S E$ & 38 & 35 & & 32 & & 47 & .021 & 11 \\
\hline
\end{tabular}

Note-RCI, response-to-cue interval.

repetition trials, RTs were 36 msec longer on response repetitions for task alternation trials, and RTs were a nonsignificant $6 \mathrm{msec}$ longer on response repetitions for task repetition trials. Response repetitions provide a benefit when both the cue and the task repeat and a cost when both the cue and the task change. The task repeti- tion condition, in which no response repetition effect is seen, may represent a balance of these two influences. This pattern of results fails to replicate the findings of Mayr and Kliegl (2003), who found benefits for response repetitions in both cue repetition and task repetition conditions.

Table 6

Comparisons of Model Fits to Data From Individual Subjects

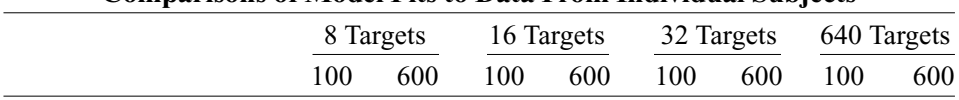

Number of Subjects Showing Significant Improvement in Fit

$\begin{array}{llllllllll}\text { Model } 2 \text { vs. Model } 2+1 & 4 & 4 & 5 & 3 & 3 & 3 & 5 & 3\end{array}$

$\begin{array}{lllllllll}\text { Model } 2 \text { vs. Model } 3 & 6 & 5 & 5 & 6 & 5 & 2 & 7 & 5\end{array}$

Number of Subjects Showing Absolute Improvement in Fit

$\begin{array}{lllllllll}\text { Model } 2+1 \text { vs. Model } 3 & 26 & 24 & 20 * & 25 & 22 & 17 * & 23 & 24\end{array}$

Note-100, 600 are response-to-cue intervals in milliseconds. *Values do not differ from those expected if fit values for the models varied at chance. 


\section{Accuracy Analyses}

Response accuracies for each task transition $\times$ SOA condition separated by target set size and RCI are shown in Table 1. Response accuracy did not vary as a function of target set size $(M \mathrm{~s}=.929, .926, .938$, and .928 for the 8-, 16-, 32-, and 640-target conditions, respectively). Task transition did affect accuracy $[F(2,248)=26.45$, $\left.M S_{\mathrm{e}}=0.008, p<.01\right]$. Accuracy was higher for cue repetitions $(M=.936)$ and task repetitions $(M=.935)$ than for task alternations $(M=.920)$. Planned contrasts showed that the task alternations differed significantly from the task repetition and the cue repetition conditions, which did not differ from each other.

\section{DISCUSSION}

In a four-cue/two-task explicit-cuing procedure, cue repetitions were substantially faster than task repetitions, which were in turn slightly faster than task alternations. This pattern of results suggests that a large portion of the standard switch costs measured using the explicit taskcuing procedure can be accounted for by a cue-encoding benefit on repetition trials, as compared with alternation trials. This finding is directly contrary to the modal interpretation of results from explicit task-cuing experiments, which interprets the difference between repetitions and alternations as reflecting the time required to perform an endogenous act of set switching when the task switches. Instead, these data are consistent with performance based on a compound-stimulus strategy (Logan \& Bundesen, 2003, in press).

The primary question addressed in the present experiment was whether the compound-stimulus strategy is implemented through episodic memory retrieval of previously experienced cue-target pairs or through semantic memory retrieval based on a compound retrieval cue provide by the cue-target pair. Critical to answering this question, the pattern of task transition effects was constant across all four target set sizes. The difference between task repetition and task alternation was the same when every target in the experiment was unique (the 640target condition) as when the targets repeated (the 8-, 16-, and 32-target conditions). Thus, it must be possible to implement the compound-stimulus strategy with a semantic memory retrieval process. Subjects do not use the compound-stimulus strategy only when they have had multiple repetitions of a cue-target pair and, thus, can retrieve a response based on relatively uninterpreted stimuli from episodic memory. They also use the compoundstimulus strategy to retrieve information from semantic memory. In addition, there is evidence that subjects also use an episodic compound-stimulus strategy when the repetition of cue-target pairs within the experiment makes this strategy available. Overall RTs and estimates of the $\mathrm{RT}_{\text {Base }}$ parameters for the different models were all shorter in the 8-, 16-, and 32-target conditions, in which targets were repeated, than in the 640-target condition, in which every target was unique. We suggest that this speed-up is due to retrieval from episodic memory (Logan, 1988).

Although the largest part of the difference in RTs between task transition conditions can be attributed to cueencoding benefits when the cue repeats, there was a small but consistent difference between the task repetition and the task alternation conditions. There are several possible interpretations of this effect. First, the difference may reflect a cost that occurs on every task alternation trial and reflects the time necessary to carry out an endogenous act of set switching. This interpretation would be in line with the standard view that the explicit task-cuing procedure captures executive control processes engaged in reconfiguring task set or with Mayr and Kliegl's (2003) revision of this view, which claims that both cue encoding and task switching affect the difference between repetitions and alternations. However, the 59-msec difference may be unrealistically small to account for a complex process of reconfiguration (see also Logan \& Bundesen, 2003, in press). Second, the difference between task repetition and task alternation conditions may reflect a relatively long set-switching process that occurs on a small percentage of trials. The compound-stimulus strategy may be used on most of the trials. If executive processes are engaged only in a subset of trials, the explicit task-cuing procedure may not be an efficient method for studying executive control processes involved in task switching. Alternatively, the difference between task repetitions and task alternations may be accounted for within the compound-stimulus strategy without hypothesizing an additional act of set switching. In the task repetition condition, the cues on trial $n$ and trial $n-1$ (e.g., "size" and "large small") are related semantically. Thus, the cue on the current trial may be primed by the semantically related cue on the previous trial, and this may speed up the cue-encoding process.

For researchers wanting to study executive control processes using task-switching procedures, it is discouraging to consider the possibility that the switch cost measure in this popular technique may not reflect an endogenous act of control. However, there may well be conditions under which endogenous acts of control are brought to bear on task performance and may be measured accurately. The use of the compound-stimulus strategy, instead of an endogenous act of control, may depend on the nature of the tasks being performed. Semantic categorizations of words, as in the present experiment, or categorizations of digits, as in Logan and Bundesen (2003, in press), involve stimuli with which subjects are familiar from contexts outside of the experiment. No learning has to take place during the experiment in order for these tasks to be performed. The tasks can be performed simply with the same semantic memory retrieval strategy. No endogenous act of task set reconfiguration is necessary. However, there may well be tasks for which applying a specialized task set configuration is necessary. For example, tasks that involve judgments of different perceptual di- 
mensions may well benefit from having attentional control settings (Folk, Remington, \& Johnston, 1992) or attention weights tuned to the currently relevant task dimension (e.g., Arrington, 2002; Arrington et al., 2003). When these tasks are presented in a task-switching experiment, subjects may well use a strategy that involves performing an endogenous act of set switching that is reflected in measures of switch costs (Arrington et al., 2003). Thus, Mayr and Kliegl (2003) may have found larger differences between task repetition and task alternation conditions than have been shown in the present experiment or in Logan and Bundesen's experiments because their tasks involved switching between perceptual dimensions of shape and color (but see Logan \& Bundesen, in press). Researchers using the explicit task-cuing procedure should pay careful attention to the individual tasks and the cognitive operations involved in carrying out these tasks when addressing questions of how control processes might be involved in switching from one task to another. Since task-switching experiments generally focus on the executive processes that carry out task switching, rather than on the subordinate level processes that carry out individual tasks (Logan \& Gordon, 2001), relatively little attention has been paid to the effects that different tasks have on the executive processes involved in task switching (but see Arrington, 2002; Arrington et al., 2003).

\section{CONCLUSION}

The explicit task-cuing procedure has been widely used to study the executive control process of task switching. However, the present results highlight the possibility that the standard switch cost measure derived from this procedure may result more from a cue-encoding benefit when the task repeats than from a cost associated with switching sets when the task changes. Subjects appear to use compound-stimulus strategies, in which the cue and the target act jointly to retrieve responses from episodic and semantic memory. The present results suggest that researchers must come to understand the conditions under which task switching does and does not require an endogenous act of control, if they hope to separate the role of the executive from those of the subordinate processes.

\section{REFERENCES}

Allport, A., Styles, E. A., \& Hsieh, S. (1994). Shifting intentional set: Exploring the dynamic control of tasks. In C. Umiltà \& M. Moscovitch (Eds.), Attention and performance XV: Conscious and nonconscious information processing (pp. 421-452). Cambridge: MA: MIT Press.

Allport, A., \& Wylie, G. (2000). Task switching, stimulus-response bindings, and negative priming. In S. Monsell \& J. Driver (Eds.), Attention and performance XVIII: Control of cognitive processes (pp. 35-70). Cambridge, MA: MIT Press.

Altmann, E. M. (2002). Functional decay of memory for tasks. Psychological Research, 66, 287-297.

ARRINGTON, C. M. (2002). Explorations in task space: Similarity effects on task switching. Unpublished doctoral dissertation, Michigan State University.
Arrington, C. M., Altmann, E. M., \& CARr, T. H. (2003). Tasks of a feather flock together: Similarity effects in task switching. Memory \& Cognition, 31, 781-789.

ARRINGTON, C. M., \& LOGAN, G. D. (2004). The cost of a voluntary task switch. Psychological Science, 15, 610-615.

FolK, C. L., REMINGTON, R. W., \& JOHNSTON, J. C. (1992). Involuntary covert orienting is contingent on attentional control settings. Journal of Experimental Psychology: Human Perception \& Performance, $\mathbf{1 8}$, 1030-1044.

KUČERA, H., \& FrANCIS, W. N. (1967). Computational analysis of presentday American English. Providence, RI: Brown University Press.

Logan, G. D. (1985). Executive control of thought and action. Acta Psychologica, 60, 193-210.

LoGAN, G. D. (1988). Toward an instance theory of automatization. Psychological Review, 95, 492-527.

LogAn, G. D., \& BUNDESEN, C. (2003). Clever homunculus: Is there an endogenous act of control in the explicit task cuing procedure? Journal of Experimental Psychology: Human Perception \& Performance, 29,575-599.

LOGAN, G. D., \& BUNDESEN, C. (in press). Very clever homunculus: Compound stimulus strategies for the explicit task-cuing procedure. Psychonomic Bulletin \& Review.

Logan, G. D., \& Gordon, R. D. (2001). Executive control of visual attention in dual-task situations. Psychological Review, 108, 393-434.

Logan, G. D., \& ZBrodoff, N. J. (1982). Constraints on strategy construction in a speeded discrimination task. Journal of Experimental Psychology: Human Perception \& Performance, 8, 502-520.

MAYR, U., \& KLIEGL, R. (2000). Task-set switching and long-term memory retrieval. Journal of Experimental Psychology: Learning, Memory, \& Cognition, 26, 1124-1140.

MAYR, U., \& KLIEGL, R. (2003). Differential effects of cue changes and task changes on task-set selection costs. Journal of Experimental Psychology: Learning, Memory, \& Cognition, 29, 362-372.

MEIRAN, N. (1996). Reconfiguration of processing mode prior to task performance. Journal of Experimental Psychology: Learning, Memory, \& Cognition, 22, 1423-1442.

Meiran, N., Chorev, Z., \& SAPIR, A. (2000). Component processes in task switching. Cognitive Psychology, 41, 211-253.

Meyer, D. E., \& Kieras, D. E. (1997). A computational theory of executive cognitive processes and multiple-task performance: Pt. 1. Basic mechanisms. Psychological Review, 104, 3-65.

Norman, D. A., \& Shallice, T. (1986). Attention to action: Willed and automatic control of behavior. In R. J. Davidson, G. E. Schwartz, \& D. Shapiro (Eds.), Consciousness and self-regulation: Advances in research and theory (Vol. 4, pp. 1-18). New York: Plenum.

Rogers, R. D., \& Monsell, S. (1995). Costs of a predictable switch between simple cognitive tasks. Journal of Experimental Psychology: General, 124, 207-231.

RUBINSTEIN, J. S., MEYER, D. E., \& EvANS, J. E. (2001). Executive control of cognitive processes in task switching. Journal of Experimental Psychology: Human Perception \& Performance, 27, 763-797.

Shoben, E. J., CECH, C. G., Schwanenflugel, P. J., \& SAILOR, K. M. (1989). Serial position effects in comparative judgments. Journal of Experimental Psychology: Human Perception \& Performance, $\underline{\mathbf{1 5}}_{2}$ 273-286.

SudEVAN, P., \& TAYlor, D. A. (1987). The cuing and priming of cognitive operations. Journal of Experimental Psychology: Human Perception \& Performance, 13, 89-103.

TownsEND, J. T., \& AshBY, F. G. (1983). Stochastic modeling of elementary psychological processes. New York: Cambridge University Press.

\section{NOTES}

1. Logan and Bundesen's (2003) experiments differed from Mayr and Kliegl's (2003) experiments in terms of the stimuli, tasks, cues, and statistical contingencies between trials. Logan and Bundesen (in press) investigated the effect of the difference in cues. Logan and Bundesen (2003) used meaningful word cues (e.g., "magnitude" and "high-low" for magnitude judgments and "parity" and "odd-even" for parity judgments), whereas Mayr and Kliegl (2003) used arbitrary letters (e.g., G 
and $\mathrm{S}$ for the color task and B and W for the form task). Logan and Bundesen (in press) compared meaningful word cues and arbitrary letter cues. They found no difference between task repetitions and task alternations with word cues, replicating Logan and Bundesen (2003). They found a substantial difference between task repetitions and task alternations with letter cues, replicating Mayr and Kliegl (2003). Unlike Mayr and Kliegl (2003), they interpreted the letter cue results in terms of an extended compound-stimulus strategy, in which subjects use task names as mediators. That is, subjects retrieve the task name associated with the letter cue and use that name and the target to retrieve the appropriate response. Logan and Bundesen (in press) suggested that task repetitions may be faster than task alternations because of facilitation from repeating the same mediator.
2. By contrast, when the comparison in goodness of fit was made between Model $2+1$, which included both a cue-encoding benefit and a setswitching cost, and Model 1, which included only a set-switching cost, the numbers of subjects that showed a significant increase in fit ranged between 10 and 23 across the various target set size $\times$ RCI conditions. Thus, the small number of subjects that showed a significant improvement in fit for Models 2+1 and Model 3 over Model 2 did not reflect an inability to find significant differences in model fits at the level of individual subjects. Rather, it suggests that Models $2+1$ and 3 did not provide a better fit than did Model 2 for most of the individual subjects' data.

(Manuscript received May 1, 2003; revision accepted for publication January 10, 2004.) 